\title{
Development of a Survival Score for Patients with Cerebral Metastases from Melanoma
}

\author{
LENA SEHMISCH ${ }^{1}$, STEVEN E. SCHILD ${ }^{2}$ and DIRK RADES ${ }^{1}$ \\ ${ }^{1}$ Department of Radiation Oncology, University of Lübeck, Lübeck, Germany; \\ ${ }^{2}$ Department of Radiation Oncology, Mayo Clinic, Scottsdale, AZ, U.S.A.
}

\begin{abstract}
Background/Aim: To develop a survival score for patients receiving whole-brain irradiation (WBI) alone for cerebral metastases from melanoma. Patients and Methods: Forty-five patients who met the required criteria were included. WBI doses had to be $>30 \mathrm{~Gy}$. Six variables were analyzed: age, gender, Karnofsky performance score (KPS), number of cerebral metastases, extracranial metastatic spread and interval from diagnosis of melanoma until WBI. In order to estimate patients' survival scores, variables showing at least a trend $(p<0.06)$ on multivariate analysis were considered. One point was assigned to each variable correlating with better survival rates and zero points to those correlating with worse survival rates. Results: By multivariate analysis, age $(p=0.002)$ achieved significance and KPS ( $p=0.056)$ showed a trend. Patients' survival scores were obtained by adding zero or one point from each variable and resulted in three groups of 0,1 or 2 points. The median survival times of these groups were one, four and ten months $(p<0.0001)$. Conclusion: A survival score was developed for patients assigned to WBI alone for cerebral metastases from melanoma. This new instrument may facilitate the decision for the appropriate WBI-program.
\end{abstract}

When cerebral metastases occur during the course of melanoma, the situation is associated with a poor outcome for the patient. Survival times of a few months were reported in the literature after the diagnosis of cerebral metastases from a melanoma. Sperduto et al. observed a survival time of 6.7 months in a study with 481 melanoma patients receiving different types of radiation therapy for cerebral metastases (1). Other studies found similar survival times (2-4).

Correspondence to: Professor Dirk Rades, MD, Department of Radiation Oncology, University of Lübeck, Ratzeburger Allee 160, 23562 Lübeck, Germany. Tel: +49 45150045401, Fax: +49 45150045404, e-mail: rades.dirk@gmx.net

Key Words: Survival score, cerebral metastases, whole-brain irradiation, melanoma, treatment selection.
Although prognosis is generally unfavorable, survival times of patients with metastases to the brain from a melanoma vary quite a lot due to different patient characteristics and types of treatment. For example, in the study of Sperduto et al., survival times ranged from 3.4 to 13.2 months (1).

For cerebral metastases therapy, different treatment options exist including surgical resection, radiosurgery, whole-brain irradiation (WBI), systemic agents or combinations of some of these modalities $(5,6)$. However, WBI alone is by far the most frequent treatment for cerebral metastases, particularly in cases of multiple lesions. Since melanoma is considered a less radiosensitive tumor type, many patients with one to three lesions are treated with radiosurgery alone $(7,8)$. However, for four or more lesions, WBI alone is the most common treatment also for patients with a melanoma. Previous studies suggested that patients with a very limited survival time should receive short-course WBI, for example with $20 \mathrm{~Gy}$ in 5 fractions over one week to keep the overall treatment time as short as possible (9). In contrast, patients who live considerably longer were reported to benefit from longer WBI-programs with higher total doses and lower doses per fraction in terms of more favorable outcomes and less pronounced late morbidities $(10,11)$. In order to provide the appropriate WBI-program for the affected patients, the treating physicians should incorporate the patient's survival time into their process of developing a personalized treatment strategy. Tumor-specific prognostic tools particularly designed for patients treated with WBI alone are required and already available for several tumor types. However, these tools would likely not be suitable for cerebral metastases from melanoma because of its relatively low radiosensitivity. Therefore, a specific survival score for patients receiving WBI alone for cerebral metastases from melanoma is needed. The development of such a tool was the aim of the present study. It included only patients who had received a WBI-dose beyond the worldwide most common regimen $30 \mathrm{~Gy}$ in 10 fractions because previous studies suggested that such a dose-escalation may improve outcomes of patients with cerebral metastases from melanoma $(12,13)$. 


\section{Patients and Methods}

Patients. In this study, we retrospectively analyzed 45 patients with cerebral metastases from a melanoma that were treated with only WBI. The total WBI doses were greater than $30 \mathrm{~Gy}$. Three patients had a single cerebral lesion, eight patients had two or three lesions and thirty-four patients four or more lesions. The following variables were analyzed regarding survival after completion of WBI: age ( $\leq 55$ vs. $\geq 56$ years, median $=55$ years), gender, Karnofsky performance score (KPS $\leq 70 v s$. KPS $\geq 80$ ), number of cerebral metastases (1-3vs. $\geq 4)$, extracranial metastatic spread (yes $v s$. no) and interval from first diagnosis of melanoma until WBI ( $\leq 24 v s$. $\geq 25$ months, median=25 months) (Table I).

Statistical analysis. The Kaplan-Meier method and the log-rank-test were used for the univariate analysis (14). Variables that showed statistical significance in the univariate analysis $(p<0.05)$ were additionally analyzed with the Cox proportional hazard model in a multivariate manner.

Survival score. Variables correlating by statistically significance $(p<0.05)$ or by a trend $(p<0.06)$ in the multivariate analysis were included in the survival score. One point was assigned to each characteristic associated with more favorable survival rates and zero points to each characteristic associated with less favorable survival rates.

\section{Results}

In the entire series of this study, the median survival time was 4 months. Survival rates at three, six and twelve months were $60 \%, 33 \%$ and $15 \%$, respectively. On univariate analysis, age at WBI $\leq 55$ years $(p<0.0001)$ and KPS $\geq 80$ $(p=0.0008)$ showed a significantly positive association with survival time (Table II). On multivariate analysis, age (Hazard Ratio 3.40, 95\%-Confidence Interval 1.55-7.88, $p=0.002$ ) showed statistical significance and KPS (Hazard Ratio 2.09, 95\%-Confidence Interval 0.98-4.46, $p=0.056$ ) showed a strong trend with survival. Hence, these variables were included in estimating the survival score for all patients. The score for an individual patient was obtained by adding the scoring points assigned to both variables, which resulted in patient groups of $0(\mathrm{~N}=12), 1(\mathrm{~N}=14)$ or $2(\mathrm{~N}=19)$ points. These three groups showed statistically significant differences in their survival times (Figure $1, p<0.0001$ ) and their median survival times were one, four and ten months, respectively. The survival rates at three, six and twelve months are shown in Table III.

\section{Discussion}

Melanoma research has gained scientific attention during the last decade including the introduction of new systemic agents and the identification of predictive clinical and preclinical markers (15-17). Due to an improvement in novel targeted therapies, melanoma patients live longer. Since the risk of
Table I. Investigated variables and their distribution.

\begin{tabular}{lcc}
\hline & $\begin{array}{c}\text { Number of } \\
\text { patients }\end{array}$ & $\begin{array}{c}\text { Proportion } \\
(\%)\end{array}$ \\
\hline Age at WBI & & \\
$\quad \leq 55$ years & 23 & 51 \\
$\quad \geq 56$ years & 22 & 49 \\
Gender & 14 & 31 \\
$\quad$ Female & 31 & 69 \\
$\quad$ Male & & \\
Karnofsky performance status & 16 & 36 \\
$\quad \leq 70$ & 29 & 64 \\
$\quad \geq 80$ & 11 & 24 \\
Number of brain metastases & 34 & 76 \\
$\quad 1-3$ & & \\
$\quad \geq 4$ & 6 & 13 \\
Extracranial metastatic spread & 39 & 87 \\
$\quad$ No & & \\
$\quad$ Yes & 22 & 49 \\
Time melanoma diagnosis to WBI & 23 & 51 \\
$\quad \leq 24$ months & & \\
$\quad \geq 25$ months & &
\end{tabular}

WBI, Whole-brain irradiation.

developing organ metastases increases with lifetime, more patients require treatment for metastatic disease. This applies also to cerebral metastases. Many of these patients are assigned to WBI alone. When WBI is indicated, different dosefractionation programs are available. The most commonly delivered program is $30 \mathrm{~Gy}$ in 10 fractions over two weeks. Radiation oncologists generally agree that patients with a markedly limited lifespan should preferentially be treated with 20 Gy in 5 fractions over one week to prevent patients spend more than necessary of their remaining lifetime with WBI (9). On the other hand, WBI with higher total dose results in better outcomes in patients with more favorable survival prognoses (11). These data highlight that the expected survival time should have an impact on the WBI-program to be considered as optimal. In order to aid the treating physicians in their process of decision making, this study aimed to develop a survival score specifically for patients with cerebral metastases from melanoma identified as suitable candidates for WBI alone. Three prognostic groups were created with statistically significant different outcomes regarding survival. Patients of the 0-point group had a median survival time of only 1 month and should, therefore, be considered for 20 Gy in 5 fractions or even better only for supportive care $(9,18)$. Patients of the 1-point group had an intermediate median survival time of 4 months and appear adequately treated with a longer-course WBI program. Since many patients with cerebral metastases from a less radiosensitive tumor such as melanoma can benefit from total doses $>30 \mathrm{~Gy}, 36 \mathrm{~Gy}$ in 12 fractions appears a reasonable option (19). Patients of the 2-point group had the 
Table II. Survival rates of the investigated variables at 3, 6 and 12 months after WBI.

\begin{tabular}{|c|c|c|c|c|}
\hline & $\begin{array}{c}\text { At } 3 \text { months } \\
(\%)\end{array}$ & $\begin{array}{l}\text { At } 6 \text { months } \\
(\%)\end{array}$ & $\begin{array}{c}\text { At } 12 \text { months } \\
(\%)\end{array}$ & $p$-Value \\
\hline \multicolumn{5}{|l|}{ Age at WBI } \\
\hline$\leq 55$ years & 78 & 57 & 31 & \\
\hline$\geq 56$ years & 41 & 9 & 0 & $<0.0001$ \\
\hline \multicolumn{5}{|l|}{ Gender } \\
\hline Female & 71 & 43 & 21 & \\
\hline Male & 55 & 29 & 12 & 0.18 \\
\hline \multicolumn{5}{|c|}{$\begin{array}{l}\text { Karnofsky } \\
\text { performance status }\end{array}$} \\
\hline$\leq 70$ & 38 & 6 & 0 & \\
\hline$\geq 80$ & 72 & 48 & 24 & 0.0008 \\
\hline \multicolumn{5}{|c|}{$\begin{array}{l}\text { Number of } \\
\text { brain metastases }\end{array}$} \\
\hline $1-3$ & 91 & 45 & 15 & \\
\hline$\geq 4$ & 50 & 29 & 15 & 0.26 \\
\hline \multicolumn{5}{|c|}{$\begin{array}{l}\text { Extracranial } \\
\text { metastatic spread }\end{array}$} \\
\hline No & 100 & 83 & 21 & \\
\hline Yes & 54 & 26 & 14 & 0.07 \\
\hline \multicolumn{5}{|c|}{$\begin{array}{l}\text { Time melanoma } \\
\text { diagnosis to WBI }\end{array}$} \\
\hline$\leq 24$ months & 45 & 32 & 19 & \\
\hline$\geq 25$ months & 74 & 35 & 13 & 0.54 \\
\hline
\end{tabular}

WBI, Whole-brain irradiation; bold, significant $p$-values.

Table III. Survival rates of the three prognostic groups at 3, 6 and 12 months after WBI.

At 3 months At 6 months At 12 months $p$-Value $(\%)$

$(\%)$

$(\%)$

\begin{tabular}{llccl}
\hline Prognostic group & & & & \\
0 points $(\mathrm{n}=12)$ & 25 & 0 & 0 & \\
1 point $(\mathrm{n}=14)$ & 64 & 21 & 0 & \\
2 points $(\mathrm{n}=19)$ & 79 & 63 & 38 & $\mathbf{< 0 . 0 0 0 1}$ \\
\hline
\end{tabular}

Bold, significant $p$-value.

most favorable survival time (median 10 months) and should, therefore, receive a longer-course WBI-program. Since these patients likely live long enough to experience WBI-related late morbidities, 40 Gy in 20 fractions appears appropriate. WBI with doses per fraction of $<3$ Gy were reported to result in a less pronounced decline in neurocognitive function than doses per fraction of $\geq 3$ Gy (10).

The median survival time of 4 months observed for the entire cohort of this study was within the range of those found in other studies of patients with WBI alone for cerebral metastases from melanoma $(1,4,20)$. In these studies, median survival times ranged between 2.9 and 6.1

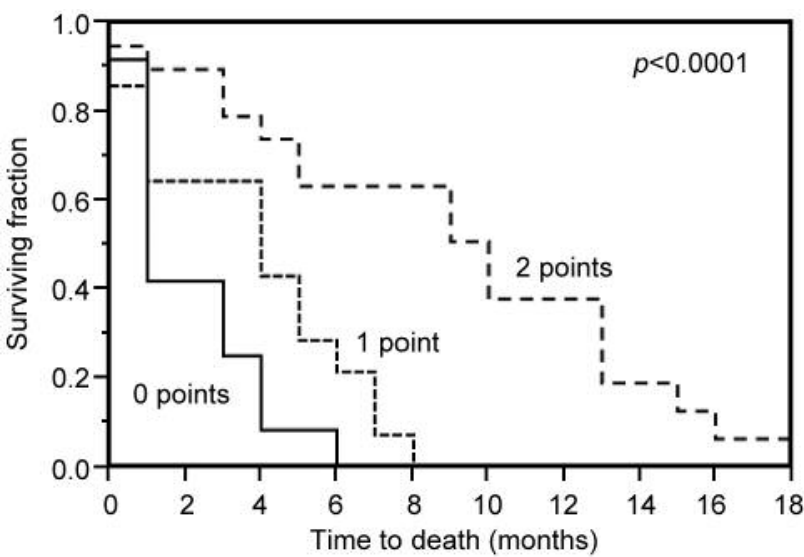

Figure 1. Kaplan-Meier curves of the three prognostic groups 0 points, 1 point and 2 points. The $p$-value was obtained using the log-rank test.

months. Nowadays, some prognostic factors for patients with cerebral metastases of melanoma are known. In the diagnosis-specific graded prognostic assessment (GPA), the variables KPS and number of brain metastases had a significant impact on survival (21). In other studies, the recursive partitioning analysis (RPA) classification was significantly correlated with survival in patients with cerebral metastases from a melanoma $(22,23)$. The RPAclassification originally introduced by Gaspar et al. in 1997 in patients with cerebral metastases from various tumor types was based mainly on KPS and age (24). Age was also identified as a significant predictor of survival in the studies of Fife et al. and Raizer et al. (4, 20). These data show some consistency with the results of the present study. However, one should bear in mind that this is a retrospective study, which may include a hidden bias, although only patients who had received WBI with doses $>30 \mathrm{~Gy}$, were included.

In summary, a survival score was developed specifically for patients with cerebral metastases from melanoma assigned to WBI alone. This new instrument may facilitate the decision for the appropriate WBI-program for an individual. Ideally, this score should be validated in a prospective cohort.

\section{Conflicts of interest}

On behalf of all Authors, the Author in correspondence states that there is no conflict of interest related to this study.

\section{References}

1 Sperduto PW, Kased N, Roberge D, Xu Z, Shanley R, Luo X, Sneed PK, Chao ST, Weil RJ, Suh J, Bhatt A, Jensen AW, Brown PD, Shih HA, Kirkpatrick J, Gaspar LE, Fiveash JB, Chiang V, Knisely JP, Sperduto CM, Lin N and Mehta M: Summary report 
on the graded prognostic assessment: An accurate and facile diagnosis-specific tool to estimate survival for patients with brain metastases. J Clin Oncol 30: 419-425, 2012.

2 Ferrel EA, Roehrig AT, Kaya EA, Carlson JD, Ling BC, Wagner A, MacKay AR, Call JA, Demakas JJ, Lamoreaux WT, Fairbanks RK, Cooke BS, Peressini B and Lee CM: Retrospective study of metastatic melanoma and renal cell carcinoma to the brain with multivariate analysis of prognostic pre-treatment clinical factors. Int J Mol Sci 17: 400, 2016.

3 Yu C, Chen JC, Apuzzo ML, O'Day S, Giannotta SL, Weber JS and Petrovich Z: Metastatic melanoma to the brain: prognostic factors after gamma knife radiosurgery. Int J Radiat Oncol Biol Phys 52: 1277-1287, 2002.

4 Raizer JJ, Hwu WJ, Panageas KS, Wilton A, Baldwin DE, Bailey E, von Althann C, Lamb LA, Alvarado G, Bilsky MH and Gutin PH: Brain and leptomeningeal metastases from cutaneous melanoma: survival outcomes based on clinical features. Neuro Oncol 10: 199-207, 2008.

5 Aoyama H, Tago $\mathrm{M}$, Shirato $\mathrm{H}$ and Japanese Radiation Oncology Study Group 99-1 (JROSG 99-1) Investigators: Stereotactic radiosurgery with or without whole-brain radiotherapy for brain metastases: Secondary nnalysis of the JROSG 99-1 randomized clinical trial. JAMA Oncol 1: 457-464, 2015.

6 Tsao MN, Rades D, Wirth A, Lo SS, Danielson BL, Gaspar LE, Sperduto PW, Vogelbaum MA, Radawski JD, Wang JZ, Gillin MT, Mohideen N, Hahn CA and Chang EL: Radiotherapeutic and surgical management for newly diagnosed brain metastasis(es): An American Society for Radiation Oncology evidence-based guideline. Pract Radiat Oncol 2: 210-225, 2012.

7 Rades D, Sehmisch L, Huttenlocher S, Blank O, Hornung D, Terheyden P, Gliemroth J and Schild SE: Radiosurgery alone for 1-3 newly-diagnosed brain metastases from melanoma: impact of dose on treatment outcomes. Anticancer Res 34: 5079-5082, 2014.

8 Huttenlocher S, Sehmisch L, Schild SE, Blank O, Hornung D and Rades D: Identifying melanoma patients with 1-3 brain metastases who may benefit from whole-brain irradiation in addition to radiosurgery. Anticancer Res 34: 5589-5592, 2014.

9 Rades D, Kieckebusch S, Lohynska R, Veninga T, Stalpers LJ, Dunst J and Schild SE: Reduction of overall treatment time in patients irradiated for more than three brain metastases. Int $\mathrm{J}$ Radiat Oncol Biol Phys 69: 1509-1513, 2007.

10 DeAngelis LM, Delattre JY and Posner JB: Radiation-induced dementia in patients cured of brain metastases. Neurology 39: 789-796, 1989.

11 Rades D, Panzner A, Dziggel L, Haatanen T, Lohynska R and Schild SE: Dose-escalation of whole-brain radiotherapy for brain metastasis in patients with a favorable survival prognosis, Cancer 118: 3853-3859, 2012.

12 Rades D, Heisterkamp C, Huttenlocher S, Bohlen G, Dunst J, Haatanen $\mathrm{T}$ and Schild SE: Dose escalation of whole-brain radiotherapy for brain metastases from melanoma. Int J Radiat Oncol Biol Phys 77: 537-541, 2010.

13 Rades D, Sehmisch L, Janssen S and Schild SE: Prognostic factors after whole-brain radiotherapy alone for brain metastases from malignant melanoma. Anticancer Res 2016, in press.

14 Kaplan EL and Meier P: Non parametric estimation from incomplete observations. J Am Stat Assoc 53: 457-481, 1958
15 Krajsová I, Arenberger P, Lakomý R, Kubala E, Březinová I, Poprach A, Št'astný M, Mužík J and Melichar B: Long-term survival with ipilimumab: Experience from a national expanded access program for patients with melanoma. Anticancer Res 35: 6303-6310, 2015.

16 Kim C, Economou S, Amatruda TT, Martin JC and Dudek AZ: Prognostic significance of microscopic tumor burden in sentinel lymph node in patients with cutaneous melanoma. Anticancer Res 35: 301-309, 2015.

17 Ramos D, Pellín-Carcelén A, Agustí J, Murgui A, Jordá E, Pellín $A$ and Monteagudo C: Deregulation of glyceraldehyde-3phosphate dehydrogenase expression during tumor progression of human cutaneous melanoma. Anticancer Res 35: 439-444, 2015.

18 Mulvenna P, Nankivell M, Barton R, Faivre-Finn C, Wilson P, McColl E, Moore B, Brisbane I, Ardron D, Holt T, Morgan S, Lee C, Waite K, Bayman N, Pugh C, Sydes B, Stephens R, Parmar MK and Langley RE: Dexamethasone and supportive care with or without whole brain radiotherapy in treating patients with non-small cell lung cancer with brain metastases unsuitable for resection or stereotactic radiotherapy (QUARTZ): results from a phase 3, non-inferiority, randomised trial. Lancet 2016, in press.

19 Rades D, Sehmisch L, Bajrovic A, Janssen S and Schild SE: Comparison of $20 \times 2$ Gy and $12 \times 3$ Gy for whole-brain irradiation of multiple brain metastases from malignant melanoma. In Vivo 2016, in press.

20 Fife KM, Colman MH, Stevens GN, Firth IC, Moon D, Shannon KF, Harman R, Petersen-Schaefer K, Zacest AC, Besser M, Milton GW, McCarthy WH and Thompson JF: Determinants of outcome in melanoma patients with cerebral metastases. J Clin Oncol 22: 1293-1300, 2004.

21 Sperduto PW, Chao ST, Sneed PK, Luo X, Suh J, Roberge D, Bhatt A, Jensen AW, Brown PD, Shih H, Kirkpatrick J, Schwer A, Gaspar LE, Fiveash JB, Chiang V, Knisely J, Sperduto CM and Mehta M: Diagnosis-specific prognostic factors, indexes, and treatment outcomes for patients with newly diagnosed brain metastases: a multi-institutional analysis of 4,259 patients. Int $\mathbf{J}$ Radiat Oncol Biol Phys 77: 655-661, 2010.

22 Harrison BE, Johnson JL, Clough RW and Halperin EC: Selection of patients with melanoma brain metastases for aggressive treatment. Am J Clin Oncol 26: 354-357, 2003.

23 Buchsbaum JC, Suh JH, Lee SY, Chidel MA, Greskovich JF and Barnett GH: Survival by radiation therapy oncology group recursive partitioning analysis class and treatment modality in patients with brain metastases from malignant melanoma: a retrospective study. Cancer 94: 2265-2272, 2002.

24 Gaspar L, Scott C, Rotman M, Asbell S, Phillips T, Wasserman T, McKenna WG and Byhardt R: Recursive partitioning analysis (RPA) of prognostic factors in three Radiation Therapy Oncology Group (RTOG) brain metastases trials. Int J Radiat Oncol Biol Phys 37: 745-751, 1997.

Received October 29, 2016

Revised November 28, 2016

Accepted December 6, 2016 